\title{
EXPERIÊNCIA DOCENTE NA EDUCAÇÃO A DISTÂNCIA
}

\author{
MARINGÁ/PR JUNHO/2018
}

\author{
Angélica Schiavão Bandeira - UNICESUMAR - angelica.bandeira@unicesumar.edu.br \\ Priscilla Campiolo Manesco Paixão - UNICESUMAR - priscilla.paixao@unicesumar.edu.br \\ Rebecca Manesco Paixão－UNICESUMAR - rebeccapaixao@gmail.com
}

Tipo: Investigação Científica (IC)

Natureza: Relatório Final de Pesquisa

Categoria: Pesquisa e Avaliação

Setor Educacional: EDUCAÇÃO SUPERIOR

\begin{abstract}
RESUMO
As atuais transformações no meio educacional geraram mudanças na medida em que a transmissão do conhecimento deixou de ser passivo e passou a ser ativo. Novas modalidades de ensino, como a Educação a Distância (EAD), trouxeram desafios aos professores em ação. Sendo assim, quais os desafios a serem superados por estes profissionais da EAD? Quais são suas percepções enquanto professores? Quais são as competências que precisarão ser desenvolvidas para obterem êxito no processo ensino-aprendizagem? Partindo destas prerrogativas, aplicou-se um questionário aos professores universitários que atuam na EAD, buscando entender sobre seu perfil acadêmico, as características que julgam importantes na prática docente e sobre as dificuldades enfrentadas no dia a dia como professor EAD. Verificou-se que muitos professores, apesar de licenciados, não estudaram sobre a EAD durante a graduação, de modo que tiveram que fazer formações continuadas para aprender sobre essa modalidade de ensino. Além disso, os professores enfrentam muitas dificuldades, como limitação de conteúdo, dificuldade na aplicação de metodologias ativas, ausência de identidade dos alunos e dentre outros. Portanto, conclui-se que os docentes devem se adequar a esta nova realidade por meio do aprendizado contínuo e incorporação de novas práticas de ensino, visando à transmissão do conhecimento de forma sistêmica.
\end{abstract}

Palavras-chave: Docência; Educação a Distância; Práxis Pedagógica. 


\section{INTRODUÇÃO}

A ideia de estudar em qualquer lugar com seu próprio ritmo e conciliando outras atividades profissionais e pessoais tem levado um maior número de pessoas a se interessar pela modalidade da Educação a Distância.

A EAD devido às suas especificidades apresenta-se como uma porta aberta e desafiadora para a promoção destes campos de estudos mediados pelos recursos didáticos sistematicamente organizados e apresentados em diferentes suportes de informações como vídeos conferências, web aula, participação em fóruns e em chats que "isolados ou combinados e veiculados pelos diversos meios de comunicação existentes" permitem a todos o acesso ao conhecimento formal (CHERMANN; BONINI, 2000, p. 17).

Com este crescimento vertiginoso da EAD nos últimos anos, vemos a necessidade de pensarmos acerca da formação dos professores que atuam nesta modalidade de ensino.

Neste sentido, a presente pesquisa investiga a importância da formação acadêmica para o exercício da docência na Educação a Distância, partindo do pressuposto que vários profissionais não possuem a qualificação necessária para exercerem tal função.

\section{REVISÃO BIBLIOGRÁFICA}

Sabe-se que a práxis pedagógica não deve ser uma atividade exclusivamente técnica, mas uma atividade crítico-reflexiva, visto que no cotidiano do professor existem problemas que requerem muito mais que conhecimentos técnicos. E é nessa perspectiva que tanto nos importa a formação docente para atuação nos diferentes níveis de ensino.

A formação do professor universitário que atuará na EAD precisa ser contínua, e assim, tanto o professor quanto as instituições de Ensino Superior (IES) devem buscar uma formação continuada para não se deterem em metodologias arcaicas, uma vez que somente a experiência não proporciona um trabalho de qualidade. É preciso antes mesmo, buscar acompanhar as mudanças que permeiam nosso meio, e a luz de teorias consolidar uma prática eficiente.

A preparação do professor e sua competência referem-se tanto a escolha dos conteúdos de ensino a serem trabalhados, como numa ampla compreensão de toda organização 
sistêmica do trabalho pedagógico, ou seja, do próprio planejamento, execução e avaliação das disciplinas de uma determinada matriz curricular.

Para Libâneo (1998), a característica mais importante da atividade profissional do professor é a mediação entre o aluno e a sociedade, entre as condições de origem deste aluno e sua destinação social, papel que cumpre promovendo as condições e os meios (conhecimentos, métodos, organização do ensino) que assegurem o encontro do discente com as disciplinas de estudo, ou seja, é necessário planejar, desenvolver e avaliar o processo de ensino para obter os resultados desejados e analisar se aquele método utilizado é suficiente para o aprendizado dos acadêmicos.

O ensino-aprendizagem nas universidades está diretamente relacionado à sociedade que está sendo desenvolvida, pois está sempre em transformação e cada profissional é também um agente transformador dessa sociedade. Para Morin (2000), "a universidade conserva, memoriza, integra e ritualiza uma herança cultural de saberes, ideias e valores, que acaba por ter um efeito regenerador, porque a universidade se incumbe de reexaminá-la e transmiti-la". A preparação do docente nesse processo é de suma importância, pois seu fazer pedagógico deve conduzir os acadêmicos não somente ao conhecimento, mas também a capacidade de modificá-los, alterá-los e inová-los conforme suas necessidades, sendo capazes de resolverem problemas que lhes serão apresentados cotidianamente.

Assim sendo, a busca pela formação de professores para atuarem na EAD é um desafio e ao mesmo tempo uma inquietação necessária.

Pimenta e Anastasiou (2002), destacam que muitas vezes, embora os professores tenham formação acadêmica e domínio da área específica de atuação, ainda sim é comum nas diferentes IES o predomínio do despreparo e até um desconhecimento científico do que seja o processo de ensino-aprendizagem na $E A D$, pelo qual passam a ser responsáveis a partir do instante em que se tornam atores diretos do processo ensino-aprendizagem de uma determinada disciplina.

O professor deve apoiar, auxiliar, investigar e principalmente mediar o aprendizado através da motivação. Deve trabalhar em forma de parceria desmistificando o conceito de que apenas o professor é o detentor do conhecimento.

$\mathrm{Na}$ maioria das vezes, os professores que por interesses variados adentram a EAD, nunca tiveram nenhum contato com os conhecimentos necessários para atuarem nesta modalidade. Por isso, não sabem relacionar, compreender e interpretar sua prática 
numa perspectiva filosófica e política da educação. Seguindo esse princípio, instituições de EAD são compostas por um corpo docente com poucas experiências, sem preparo e sem contato com a verdadeira formação pedagógica que envolve os conhecimentos teóricos e práticos desta modalidade.

\section{METODOLOGIA}

A presente pesquisa traz em seu bojo uma pesquisa qualitativa de estudo de caso. Bracht et al (2008, p. 21) afirma que "casos são representações textuais da realidade que colocam o leitor no papel de participante da situação". Sua unidade de análise varia consideravelmente, assim o levantamento de dados acerca dos professores que atuam na EAD, foi conduzido por meio da aplicação de um questionário a 20 professores universitários dessa modalidade de ensino, escolhidos voluntariamente, os quais tiveram que responder os seguintes questionamentos:

- Formação acadêmica e maior titulação;

- Idade;

- Sexo;

- Sua atuação como professor abrange quais etapas do ensino?;

- Há quanto tempo é professor na EAD?;

- Estudou sobre a EAD durante a formação acadêmica?;

- Em que momento aprendeu as técnicas necessárias a docência?;

- O que considera mais importante para ser um professor de EAD?;

- Quais as maiores dificuldades encontradas no dia a dia enquanto professor EAD?

Após os professores responderem ao questionário, analisaram-se os dados coletados, observando a frequência das respostas dos sujeitos para a análise qualitativa.

\section{RESULTADOS E DISCUSSÕES}

Considerando a formação inicial e continuada de professores no âmbito da Educação Superior cabe destacar a importância do professor da Educação a Distância neste quadro. Embora tenha no Sistema Nacional de Educação a preocupação em gerar políticas de incentivo a formação qualificada de docentes, vemos ainda profissionais iniciando sua experiência docente na EAD sem sequer conhecer suas especificidades.

Isso foi observado nos dados levantados nessa pesquisa, visto $74 \%$ dos entrevistados não estudaram sobre essa modalidade de ensino em sua formação inicial (Figura 1). 


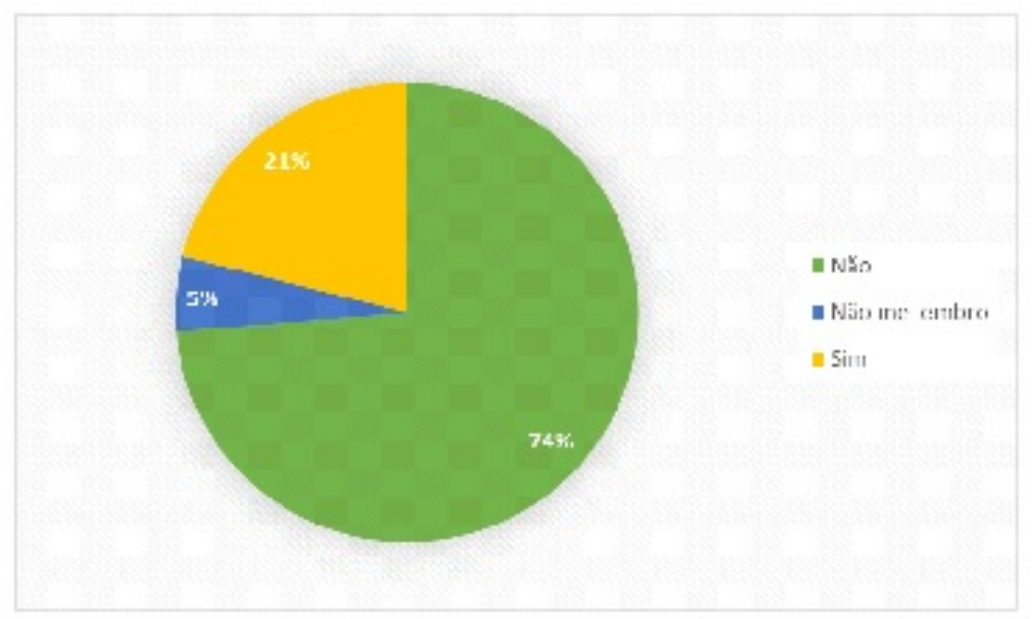

Figura 1: Durante a graduação você estudou sobre a EaD? Fonte: Elaborado pelas autoras (2018).

Nossa reflexão acerca da prática docente encontra, ainda, uma importante consideração: a maioria desses professores cursaram uma Licenciatura, e que não necessariamente englobou as diferentes modalidades de ensino, como a EAD. Além disso, chama-nos a atenção que $26 \%$ dos professores participantes nunca realizaram cursos relacionados à formação docente (Figura 2).

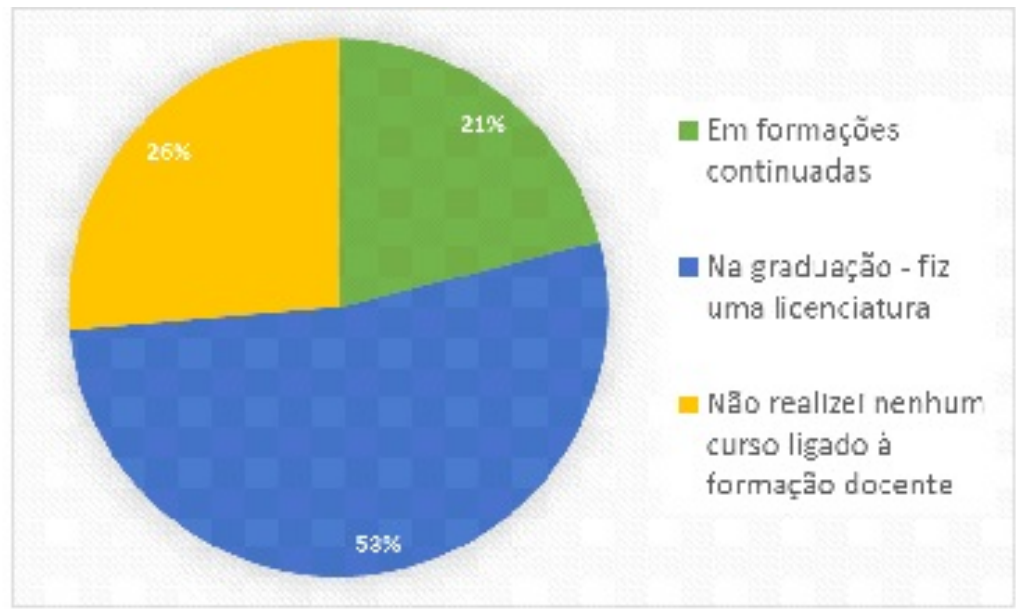

Figura 2: Em que momento você aprendeu/estudou as técnicas necessárias à docên cia?

Fonte: Elaborado pelas autoras (2018).

Quanto ao tempo da experiência em EAD (Figura 3), pode-se observar que a grande maioria trabalha a mais de um ano, cuja experiência atua como facilitadora na hora de atuar nessa modalidade de ensino. 


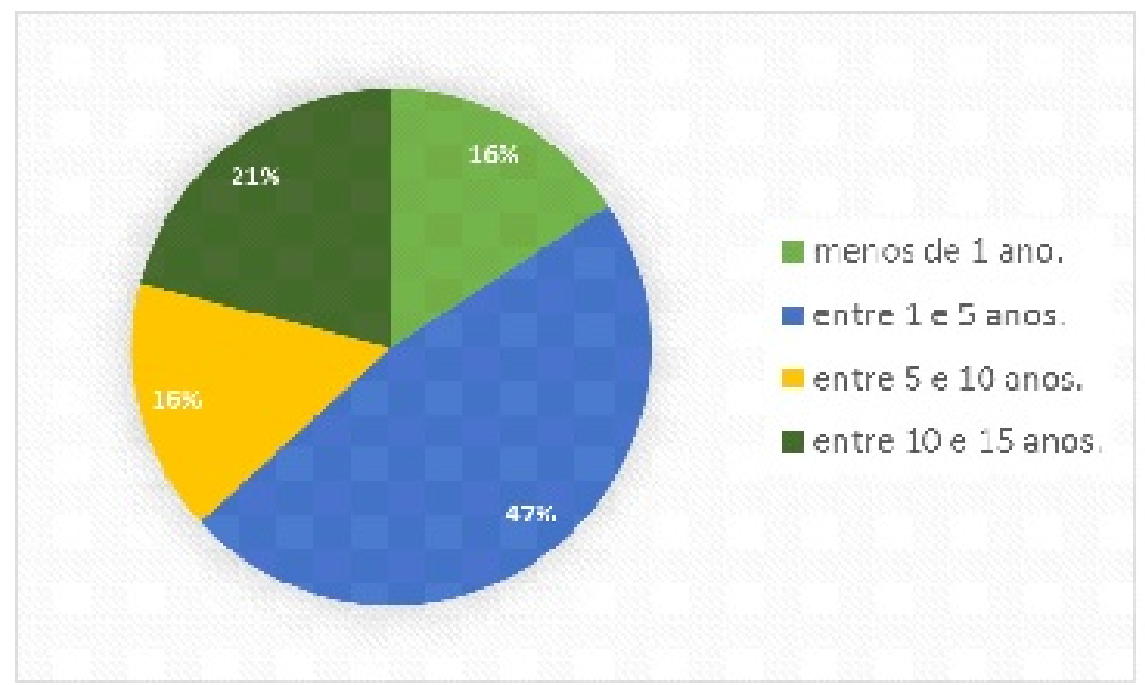

Figura 3: Há quanto tempo é professor na Educação a Distância? Fonte: Elaborado pelas autoras (2018).

Também se verificou que dos professores universitários entrevistados, a grande maioria atua em outros níveis de ensino como pós-graduação, ensino médio e ensino fundamental (Figura 4), estes na modalidade presencial, o que por muitas vezes pode trazer dificuldades no ensino a distância, visto que nem sempre a mesma tática pedagógica funciona para o ensino presencial e a distância.

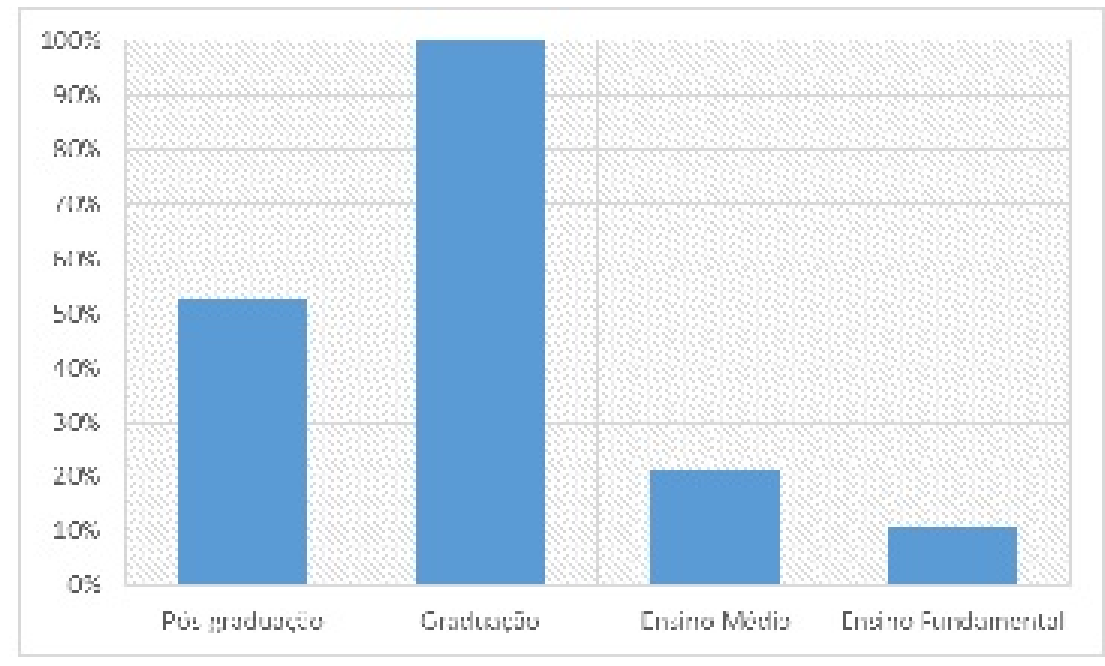

Figura 4: Atuação no ensino.

Fonte: Elaborado pelas autoras (2018).

Acerca das atribuições que um professor EAD deve ter, a didática é considerada uma das mais importantes, na opinião dos entrevistados, além disso, também se cita o conhecimento acerca do conteúdo a ser trabalhado, clareza, dinamismo, capacidade de comunicação e interação com os alunos via ambiente virtual e metodologia bem definida. 
Já quanto às dificuldades enfrentadas na EAD, os professores citaram a dificuldade da aplicação de metodologias ativas, falta de contato direto com o aluno, carga horaria reduzida, superficialidade dos temas abordados e a discrepância em relação ao nivelamento dos alunos em relação aos conteúdos prévios.

Dadas essas dificuldades elencadas pelos entrevistados, torna-se importante que os professores juntamente com as IES, busquem aperfeiçoamentos para que possam trabalhar da melhor maneira possível na EAD, buscando transmitir o conteúdo aos alunos com domínio e objetividade.

Neste sentido, para Pimenta e Anastasiou (2002, p. 259):

\footnotetext{
O avançar no processo de docência e do desenvolvimento profissional, mediante a preparação pedagógica não se dará em separado de processos de desenvolvimento pessoal e Institucional: este é o desafio a ser hoje, considerado na construção da docência no ensino superior.
}

Essa verificação apadrinha a discussão que propomos da formação continuada a favor dos serviços educacionais na modalidade a distância. Sendo assim, a especialidade da docência faz parte do projeto institucional da educação cuja experiência e habilitação deve ser articulada pelo docente no cultivo e permanência da sua competência universitária.

Verificamos então, que a universidade deve propor momentos reflexivos onde o objetivo principal da mediação é formar cidadãos que saibam construir e reconstruir os seus conhecimentos aperfeiçoando sua individualidade.

A formação pedagógica surge dos trabalhos pedagógicos e pela qualidade que estes trabalhos estão sendo percebidos no âmbito do processo ensino-aprendizagem e também na ação do docente nas circunstâncias previstas ou não em seu plano didático.

Diante disso, é de suma importância que as universidades invistam na qualidade da formação de seus docentes possibilitando a busca de novos conhecimentos e se aprofundando nas teorias passadas para entender e compreender o processo transitório da educação. É necessário também que a mesma permita a transformação da identidade docente, desperte o interesse e a capacidade de modificar a realidade das aulas ministradas e crie um ambiente amplo em pesquisas científicas, preparando 0 docente para sua atuação na modalidade a distância para que este se transforme em um profissional inovador que saiba conduzir os acontecimentos corriqueiros de seu ambiente de trabalho com competência. 


\section{CONSIDERACÕES FINAIS}

Sabemos que o professor é um multiplicador de conhecimentos e, por isso, vemos como de grande importância o constante aperfeiçoamento da prática do professor tanto em relação às inovações tecnológicas, como nas tendências da educação diante destas.

Uma vez que os cursos de formação docente, em sua maioria, ainda não se adequaram a esta nova realidade, cabem às IES e aos seus docentes atuantes na educação a distância realizarem formações continuadas que permitam aos seus atores dominarem as ferramentas necessárias à práxis pedagógica, bem como discutirem e encontrarem caminhos sólidos que permitam qualificar esta modalidade de ensino.

Só assim, o professor que trabalha com Educação a Distância terá a possibilidade de exercer sua função de mediador, orientador dos acadêmicos na construção dos seus próprios conhecimentos.

\section{REFERÊNCIAS BIBLIOGRÁFICAS}

BRACHT, V.; CAPARROZ, F. E.; FONTE, S. S. D.; FRADE, J. C.; PAIVA, F.; ELLET, W. Manual de estudo de caso: como ler, discutir e escrever casos de forma persuasiva. Porto Alegre: Bookman, 2008.

CHERMANN, Maurício; BONINI, Luci Mendes. Educação a distância. Novas tecnologias em ambientes de aprendizagem pela Internet. São Paulo: Universidade Braz Cubas, 2000.

LIBÂNEO, J. C. Didática. São Paulo: Cortez, 1998.

MORIN, E. Complexidade e transdisciplinaridade: a reforma da universidade e do ensino fundamental. Natal: EDUFRN, 2000.

PIMENTA, S. G.; ANASTASIOU, Lea das Graças Camargo. Docência no ensino superior. São Paulo: Cortez, 2002. 